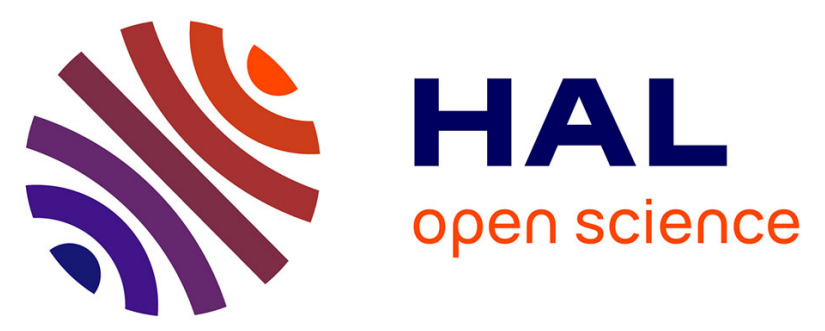

\title{
Microstructural features controlling the variability in low-cycle fatigue properties of alloy Inconel 718DA at intermediate temperature
}

Damien Texier, Ana Casanova Gómez, Stéphane Pierret, Jean-Michel Franchet, Tresa M. Pollock, Patrick Villechaise, Jonathan Cormier

\section{To cite this version:}

Damien Texier, Ana Casanova Gómez, Stéphane Pierret, Jean-Michel Franchet, Tresa M. Pollock, et al. Microstructural features controlling the variability in low-cycle fatigue properties of alloy Inconel 718DA at intermediate temperature. Metallurgical and Materials Transactions A, 2016, 47 (3), pp.1096 - 1109. 10.1007/s11661-015-3291-8 . hal-01644848

\author{
HAL Id: hal-01644848 \\ https://hal.science/hal-01644848
}

Submitted on 13 Dec 2017

HAL is a multi-disciplinary open access archive for the deposit and dissemination of scientific research documents, whether they are published or not. The documents may come from teaching and research institutions in France or abroad, or from public or private research centers.
L'archive ouverte pluridisciplinaire HAL, est destinée au dépôt et à la diffusion de documents scientifiques de niveau recherche, publiés ou non, émanant des établissements d'enseignement et de recherche français ou étrangers, des laboratoires publics ou privés. 


\title{
Microstructural Features Controlling the Variability in Low-Cycle Fatigue Properties of Alloy Inconel 718DA at Intermediate Temperature
}

\author{
DAMIEN TEXIER, ANA CASANOVA GÓMEZ, STÉPHANE PIERRET, \\ JEAN-MICHEL FRANCHET, TRESA M. POLLOCK, PATRICK VILLECHAISE, \\ and JONATHAN CORMIER
}

The low-cycle fatigue behavior of two direct-aged versions of the nickel-based superalloy Inconel 718 (IN718DA) was examined in the low-strain amplitude regime at intermediate temperature. High variability in fatigue life was observed, and abnormally short lifetimes were systematically observed to be due to crack initiation at (sub)-surface non-metallic inclusions. However, crack initiation within (sub)-surface non-metallic inclusions did not necessarily lead to short fatigue life. The macro- to micro-mechanical mechanisms of deformation and damage have been examined by means of detailed microstructural characterization, tensile and fatigue mechanical tests, and in situ tensile testing. The initial stages of crack micro-propagation from cracked non-metallic particles into the surrounding metallic matrix occupies a large fraction of the fatigue life and requires extensive local plastic straining in the matrix adjacent to the cracked inclusions. Differences in microstructure that influence local plastic straining, i.e., the $\delta$-phase content and the grain size, coupled with the presence of non-metallic inclusions at the high end of the size distribution contribute strongly to the fatigue life variability.

\section{INTRODUCTION}

THE nickel-based superalloy Inconel 718 (IN718) exhibits excellent creep and fatigue properties at intermediate and high temperature. This high level of resistance is conferred by metastable $\gamma^{\prime \prime}-\mathrm{Ni}_{3} \mathrm{Nb}$ and $\gamma^{\prime}-\mathrm{Ni}_{3}(\mathrm{Ti}, \mathrm{Al})$ precipitates embedded in a $\gamma$-matrix. ${ }^{[1-3]}$ Moreover, its good forgeability and the wide windows for strengthening heat treatments make this material an

DAMIEN TEXIER, Postdoctoral Fellow, is with the Institut Pprime - UPR CNRS 3346 - ISAE-ENSMA, Téléport 2, 1 avenue Clément Ader, BP 40109, 86961 Futuroscope-Chasseneuil Cedex, France, and also with the Materials Department, University of California Santa Barbara, Santa Barbara, CA 93106, and also now with the Mechanical Engineering Department, Ecole de Technologie Supérieure, 1100 Rue Notre-Dame Ouest, Montréal H3C 1K3, QC, Canada. Contact e-mail: damien.texier@etsmtl.ca ANA CASANOVA GÓMEZ, Ph.D. Student, is with the Institut Pprime - UPR CNRS 3346 - ISAE-ENSMA and also now with the Department of Materials Science and Metallurgy, University of Cambridge, 27 Charles Babbage Road, Cambridge CB3 0FS, UK. STÉPHANE PIERRET, Engineer, is with the Mechanics of Materials, Snecma-SAFRAN Group, Site de Villaroche, Rond-Point René Ravaud, 77550 Moissy-Cramayel, France. JEAN-MICHEL FRANCHET, Engineer, is with the Materials \& Process, Safran SA, SafranTech., SAFRAN Center of R\&T, 78114 Magny-les-Hameaux, France. TRESA M. POLLOCK, ALCOA Professor of Materials, is with the Materials Department, University of California Santa Barbara. PATRICK VILLECHAISE, Director of Research (French National Centre for Scientific Research), and JONATHAN CORMIER, Associate Professor, are with the Institut Pprime - UPR CNRS 3346 - ISAE-ENSMA. Contact e-mail: jonathan.cormier@ensma.fr attractive choice for the manufacture of physically large industrial components. The alloy IN718 is commonly used for high-pressure turbine disks in aircraft engine applications which undergo severe steady and alternating stresses, and this alloy may compose approximately one-third of the weight of an entire engine. ${ }^{[4-6]}$ Improvement of the mechanical properties of IN718 alloys has been strongly pursued over the past few decades through an optimization of either the chemical composition or the forging fabrication process. Derived from this latter optimization method, the direct-aged version of this alloy (IN718DA) is processed by applying the aging treatment directly after the last forging stage, without any intermediate solution heat treatment. ${ }^{[7]} \mathrm{A}$ finer grain size and a higher amount of the strengthening $\gamma^{\prime \prime}-\mathrm{Ni}_{3} \mathrm{Nb}$ phase can be obtained using such a thermomechanical route, in addition to beneficial residual strain hardening generated by the forging operation. This fabrication process leads to much higher yield stress, which in principle should translate to better fatigue properties. ${ }^{[8]}$ Although the low-cycle fatigue (LCF) durability IN718DA is enhanced in comparison with the standard version of IN718, a higher scatter in LCF lifetimes has been observed for IN718DA at intermediate temperature in the low-strain range. ${ }^{[6]}$ Probability-of-failure curves obtained from a series of strain controlled LCF tests $\left(R_{\varepsilon}=0.05\right)$ performed at a temperature below $773 \mathrm{~K}\left(500{ }^{\circ} \mathrm{C}\right)$ on fine-grain microstructures are depicted in Figure 1. ${ }^{[9]}$ Curves of iso-alternating stress amplitudes were normalized by the 0.2 pct yield strength measured for the different batches of specimens. The variability at low alternating stress amplitude is clearly 
highlighted by the low-fatigue-life plateau in the probability-of-failure curves. Fractographic analyses show that very short LCF lifetimes (below 50,000 cycles) are exclusively associated with (sub)-surface initiation sites, while longer lifespans can be related to either internal or (sub)-surface initiation sites. The low-fatigue-life plateau might indicate differences in initiation/early stage of crack propagation modes. The extension of the plateau decreases with the stress level to mainly disappear under high applied strain amplitudes, whose initiation site is essentially at a (sub)-surface location. Späth et al. attributed abnormally short fatigue life at $623 \mathrm{~K}$ $\left(350{ }^{\circ} \mathrm{C}\right)$ to a crack initiation mechanism at (sub)-surface carbides for "as-machined specimens" with microstructures finer than ASTM11. ${ }^{[6]}$ However, crack initiation sites at (sub)-surface non-metallic inclusions (NMIs), in the form of either isolated particles or clusters, have been commonly reported in the literature for a wide range of temperatures for 718 alloys without any premature fatigue failure. ${ }^{[6,8-16]}$ Although the variability in lifespan is a first-order consideration for the design of rotating aeronautical components, the complex relationship between forging parameters, microstructures, specimen machining conditions, and LCF properties has not been clearly established in the literature. No straightforward trends are available for the explanation of the wider variability in fatigue durability considering the NMI size distribution, the $\delta$-phase content, and the strengthening precipitation state.

The aim of the present study is to investigate this variability in the low-strain range and especially the abnormally short LCF lifetimes related to (sub)-surface initiation sites. The LCF properties were investigated on materials extracted from different locations of a prototype turbine disk processed by the direct-aged approach. The LCF life variability was analyzed by means of a

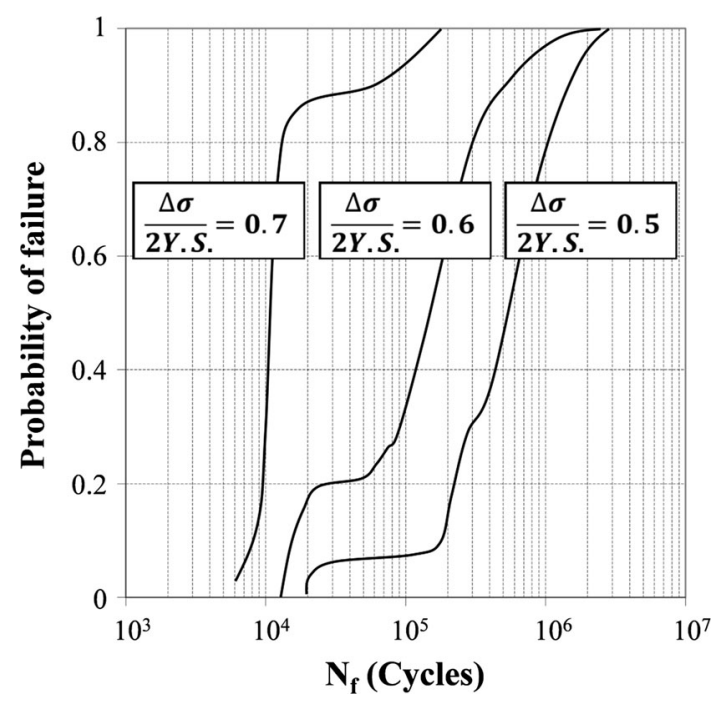

Fig. 1-Probability of failure (P.o.f) of ASTM 10-13 microstructure IN718DA for different stress levels at an intermediate temperature $\left(R_{\varepsilon}=0.05\right.$ and $\left.f=1 \mathrm{~Hz}\right){ }^{[9]}$ complete microstructural characterization of the different regions and also conventional mechanical tests and in situ tests. The results are discussed and compared to the numerous references in the literature on the effect of microstructural variables on the crack growth and fatigue life of 718 alloys, i.e., the grain size distribution, ${ }^{[6,12,16-19]}$ the $\gamma^{\prime \prime}$ precipitation state, ${ }^{[1,2,18,20-23]}$ the NMI size distribution, ${ }^{[10-14,24-28]}$ and the $\delta$-phase content. ${ }^{[12,29-31]}$ Our main interest in the present study concerned the microstructural features governing LCF "weak links." Particular attention was paid to the microstructure in the vicinity of NMIs, as this is likely to influence the short LCF lifespans.

\section{EXPERIMENTAL CONDITIONS}

\section{A. Materials}

The Inconel 718 direct-aged (IN718DA) material used in this study was extracted from an aeronautical turbine disk provided by Snecma-SAFRAN group. The nominal composition of this alloy is in accordance with premium quality (PQ) NC19FeNb (AFNOR norm) for critical aeronautical components. The microstructure and the mechanical properties of IN718DA are closely linked with the different forging operations during the disk manufacture. The $\gamma^{\prime} / \gamma^{\prime \prime}$ hardening precipitation state is conferred by the aging heat treatment applied directly after the forging operation and which results in the "direct-aged" microstructure. The occurrence of the stable phase $\delta-\mathrm{Ni}_{3} \mathrm{Nb}$ proportionally decreases the content of its metastable allotropic form $\gamma^{\prime \prime}-\mathrm{Ni}_{3} \mathrm{Nb}$. Primary and secondary carbides, nitrides, and carbonitrides are present within the specification for premium quality Ni-based superalloys. Two different regions of the turbine disk were investigated, the rim and the bore regions, corresponding to the thinnest and thickest areas of the disk, respectively. The schematic layout of the turbine disk in Figure 2(a) illustrates the position and orientation of the specimens extracted and analyzed. The rim and bore regions correspond to the pink and blue areas in Figure 2(a), respectively. This color code will be kept in the following parts for reading convenience.

\section{B. Specimens Preparation}

Four different specimen geometries were used to perform both tensile and fatigue experiments at intermediate temperature and in situ room-temperature tensile tests (Figure 2). All specimens were tangentially machined out from the bore and the rim regions of a forged turbine disk by electro-discharge machining and lathe-turning. Particular care was taken during the final steps of the lathe-turning machining in order to limit superficial residual stresses. After machining, specimens dedicated for LCF and monotonic tensile experiments (Figures 2(b) and (c)) were automatically ground down to a $4000 \mathrm{SiC}$ paper to remove at least $0.2 \mathrm{~mm}$ in the diameter. Then, the cylindrical gages were manually polished to a mirror finish (with a $1 \mu \mathrm{m}$ diamond spray) 

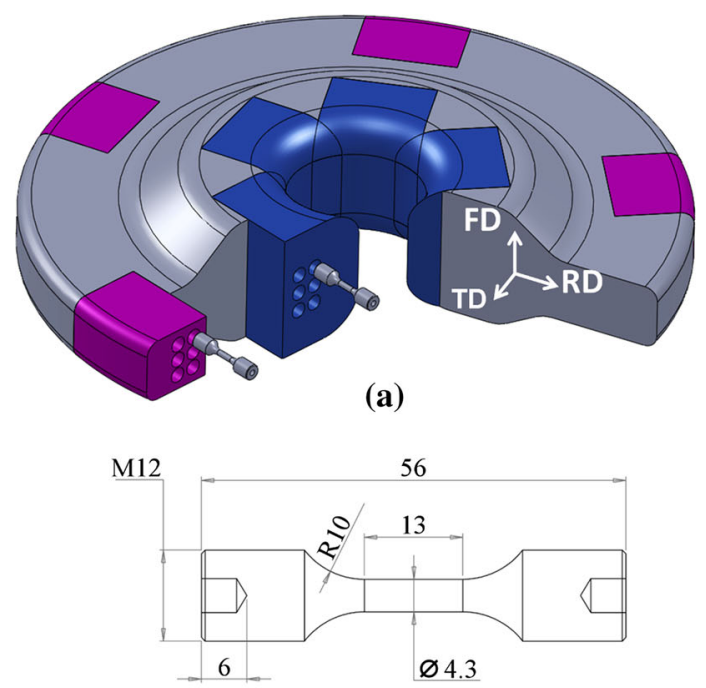

(b)

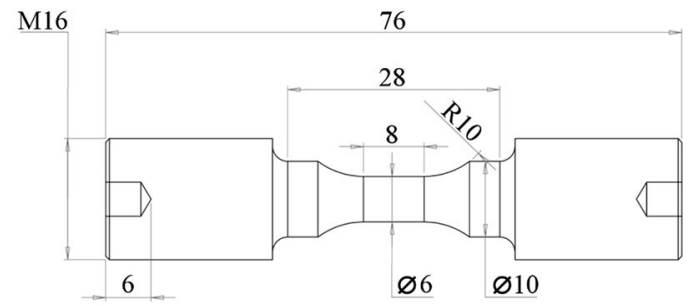

(c)

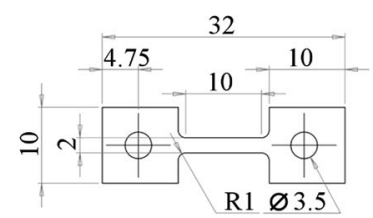

(d)

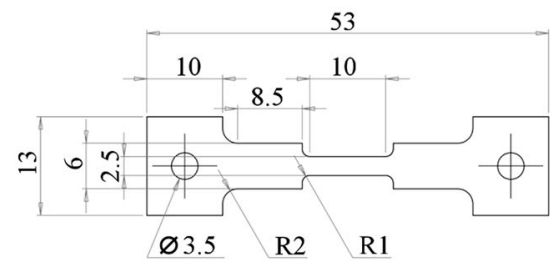

(e)

Fig. 2-(a) Schematic representation of a turbine disk and of LCF specimens extracted from the rim region (pink region of the disk) and the bore region (blue region of the disk), (b) Specimen geometry dedicated to LCF and tensile tests at intermediate temperature, (c) Specimen geometry of interrupted LCF test at intermediate temperature, (d) Specimen geometry dedicated to in situ tensile test at room temperature, (e) Geometry of in situ tensile specimen machined out from a pre-cycled LCF specimen (c) (Color figure online).

in order to avoid any premature failure from surface scratches. Flat specimens (Figure 2(d)) dedicated for in situ tensile tests of the "as received" material were directly machined out from the disk by electrodischarge machining. Flat pre-cycled specimens (Figure 2(e)) were sliced from macroscopic cylindrical specimens (Figure 2(c)) by electro-discharge machining. All flat specimens were manually ground and polished down to $1 \mu \mathrm{m}$ diamond spray and then electrochemically polished at $277 \mathrm{~K}\left(4^{\circ} \mathrm{C}\right)$ in a solution of $10 \mathrm{vol}$ pet perchloric acid in methanol under $45 \mathrm{~V}$. This latter step effectively removes any residual stresses from mechanical polishing.

\section{Microstructural Characterization Methods}

Different microstructural features, such as the grain structure and the distribution of carbides, nitrides, carbonitrides, and $\delta$-phase, were characterized using the back-scattered electron mode of a $\mathrm{JEOL}^{\mathrm{TM}} \mathrm{JSM}$ $7000 \mathrm{~F}$ in the 20 to $25 \mathrm{kV}$ range. The microstructure was revealed by electropolishing, which consumes the $\gamma$ matrix preferentially with respect to NMIs and $\delta$-phase. Contrast was also sufficient to highlight the grain structure of the different microstructure features: $\delta$ precipitates (see, e.g., Figure 3) and carbides appear lighter than the $\gamma$ matrix, while nitrides appear darker (see, e.g., Figure 5(a)). The $\delta$-phase fraction and morphology were determined using the $\operatorname{Visilog}^{\circledR}$ image analysis software and a specific algorithm developed at the Institute Pprime. ${ }^{[32]}$ A similar stereological characterization was undertaken to determine the different non-metallic inclusion sizes and their surface fraction.

Both "large area" and "local" electron backscattering diffraction (EBSD) scans were performed with an $\mathrm{OIM}^{\mathrm{m}}$ software from EDAX acquisition setup equipped on a conventional SEM of JEOL ${ }^{\mathrm{TM}} 6100$ type. "Large area" scans sampled a $300 \times 1100 \mu \mathrm{m}^{2}$ area for both the rim and the bore regions with a $0.5 \mu \mathrm{m}$ step square sampling pattern. To cover this area, 6 scans $\left(300 \times 200 \mu \mathrm{m}^{2}\right)$ were performed with a 10 pct surface overlap. Both the nickel phase $(\gamma$ matrix $)$ and the $\delta$-phase were indexed. "Local" scans were performed on $85 \times 85 \mu \mathrm{m}^{2}$ areas with a $0.1 \mu \mathrm{m}$ step squared pattern.

\section{Conventional Mechanical Testing}

Intermediate temperature tensile and fatigue experiments were conducted on an Instron ${ }^{\mathrm{TM}} 1362$ electromechanical fatigue machine equipped with a radiant furnace. The temperature was first calibrated using a dedicated specimen for each geometry with three K-type thermocouples along the gage zone. Monotonic tensile tests were performed under pure displacement control at an initial strain rate of $10^{-3} \mathrm{~s}^{-1}$ and the strain continuously measured with a high-temperature contact extensometer. LCF fatigue experiments were performed under pure strain control, with a positive strain ratio $R_{\varepsilon}=0.05$, using a $1 \mathrm{~Hz}$ triangular cycle and strain continuously measured with a high-temperature contact extensometer. After 85,000 cycles and up to failure, LCF experiments were switched to pure stress control, with the stress ratio defined by the minimum and maximum stabilized stress measured over the previous cycles. Under stress control, the frequency of the LCF experiments was increased to $10 \mathrm{~Hz}$. Some interrupted LCF tests were conducted to investigate the mechanisms governing crack initiation on NMIs and the kinetics of damage development. 

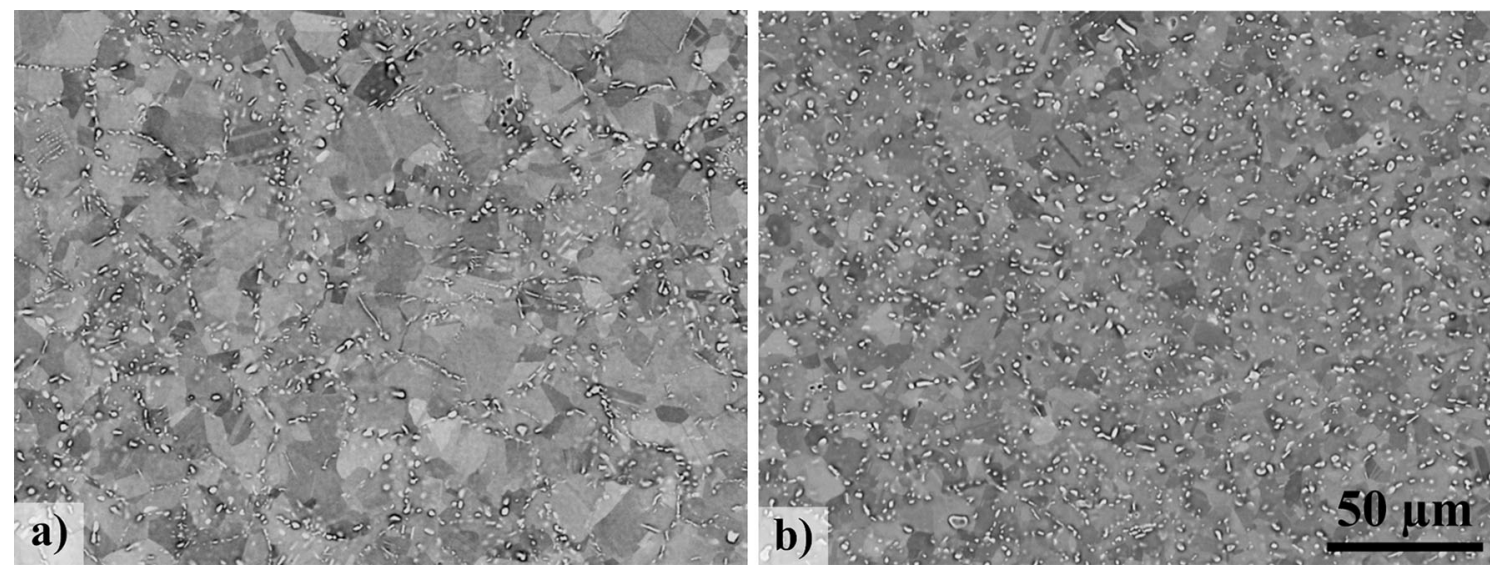

Fig. 3-Microstructure of the different regions of the turbine disk (white precipitates correspond to $\delta$-Ni ${ }_{3} \mathrm{Al}$ ): $(a)$ Bore region, $(b)$ Rim region.

\section{E. In situ Tensile Testing for Micro-mechanical Damage Characterization}

In situ SEM tensile experiments were conducted on "as received" and pre-cycled small flat specimens (Figures 2(d) and (e)). Tests were performed using a JEOL $^{\text {TM }} 6100$ conventional SEM equipped with a DEBEN micro-machine. No extensometer can be used during in situ testing due to geometrical constraints; therefore, ex situ tests were previously performed on the DEBEN micro-machine with a contact extensometer located on the gage zone of the specimen to precisely draw the room-temperature stress-strain curves of the bore and rim regions of the disk. A low-strain rate (in the order of $10^{-4} \mathrm{~s}^{-1}$ ) was used so as to be able to stop the loading step by step at pre-determined stress levels. This latter condition is necessary for observation in order to avoid the vibration induced by load control of the specimen. Several areas were observed for every given elongation/stress level. Interruptions were performed at 500, $1000 \mathrm{MPa}$, then every $25 \mathrm{MPa}$ up to $1400 \mathrm{MPa}$ and every $15 \mathrm{MPa}$ over $1400 \mathrm{MPa}$. A population of 150 to 200 NMIs, predominantly secondary carbides, was followed for each step. The inclusions were randomly chosen along the length of the gage zone in order to represent various aspects of the NMIs (size and morphology).

\section{RESULTS}

\section{A. Microstructure Analyses}

The microstructure of IN718DA is closely linked to the thermomechanical conditions during the forging process. The rim and the bore regions correspond to the areas of the forged turbine disk where maximum variability in the microstructure is expected. As depicted in Figure 3, SEM observations highlight slight differences in microstructural features, i.e., grain size, $\delta$ phase content, and morphology. Quantitative microstructural characterizations were conducted on both regions and are presented in the following sections.

\section{Grains size distribution}

"Large area" EBSD measurements were conducted in order to determine the grain size distribution in the two regions of the turbine disk. Figure 4 shows the inverse pole figure (IPF) maps of the rim and the bore regions according to the loading direction. Pseudo-symmetry corrections were performed to remove twins for grain size consideration. A finer grain size structure is evidenced in the rim region in comparison with the bore. Grain size histograms are presented in Figures 4(b) and (d) and highlight a higher mean value of the grain size with a greater standard deviation in the bore region (mean grain size of 11.4 and $7.7 \mu \mathrm{m}$ in the bore and rim regions, respectively). The equivalent diameters of the coarsest grains are 26 and $18 \mu \mathrm{m}$ for the bore and rim regions, respectively. In addition, the bore region appeared to retain microstructural heterogeneities from the dendritic/interdendritic segregation during solidification, as opposed to the microstructural homogeneity of the rim region. Local EBSD measurements from the dendritic and interdendritic regions of the bore area were cropped for comparison. Coarser grains were observed in the dendritic region (mean grain size of $12.4 \mu \mathrm{m}$ ) in comparison with the interdendritic region (mean grain size of $9.4 \mu \mathrm{m}$ ).

\section{2. $\delta$-Phase precipitation}

As reported in the previous section, a difference in grain size structure was measured between the rim and the bore regions, but also between the dendritic and interdendritic regions within the bore location. Similar variations were observed for the $\delta$-phase, with differences in terms of both content and morphology (see, e.g., Figure 3). Fine globular $\delta$ precipitates were homogeneously distributed within the rim microstructure, while the microstructure of the bore region is more complex. In the interdendritic area, the $\delta$-phase morphology is more rounded. In contrast, the $\delta$-phase in the dendritic area adopts a platelet morphology around the original austenitic grains prior to recrystallization.

Quantitative analyses of the $\delta$-phase content were also conducted via image analyses. Statistically, the rim region shows a higher area fraction of $\delta$-phase 

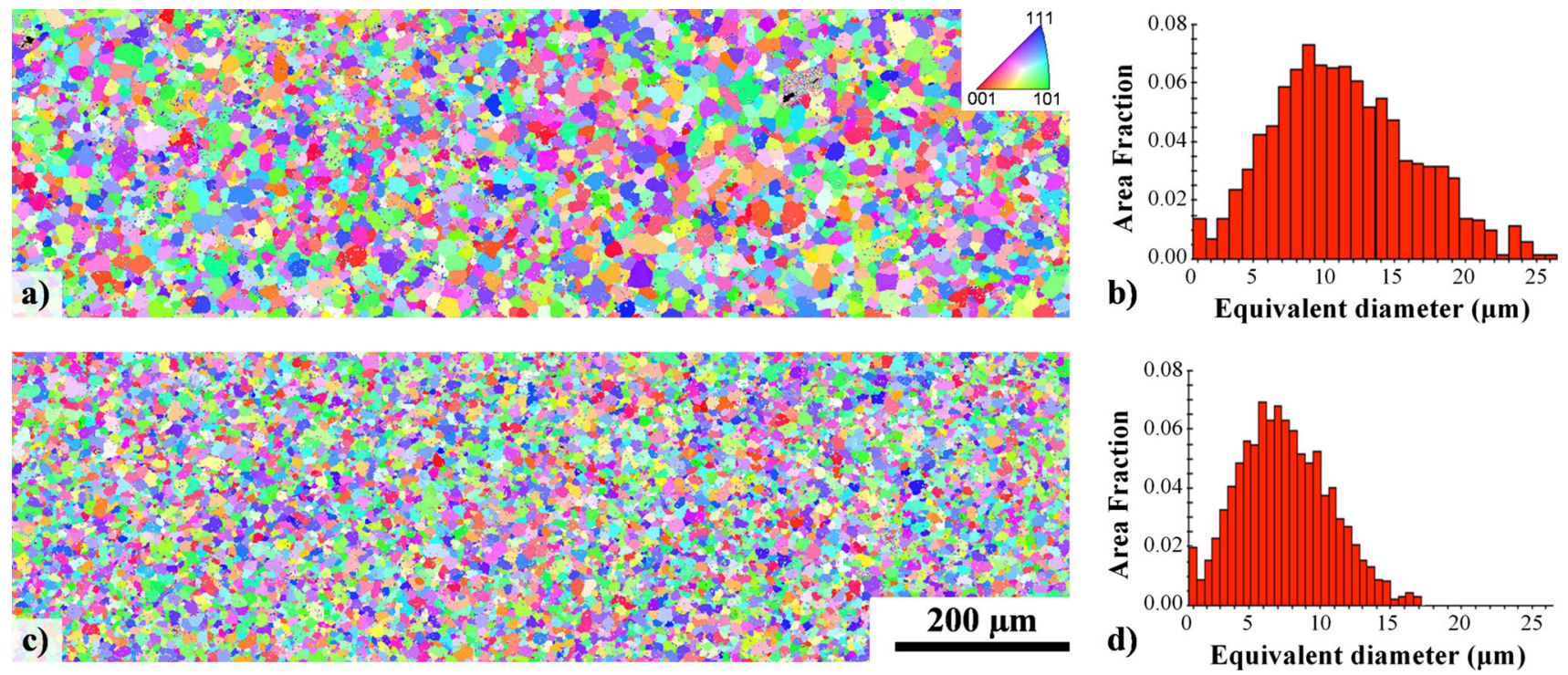

Fig. 4-Grain microstructure of the different regions of the disk represented as IPF maps according to the TD direction (loading direction): (a) Bore region, (c) Rim region, Grain size histogram for the different regions of the disk: $(b)$ Bore region, $(d)$ Rim region.
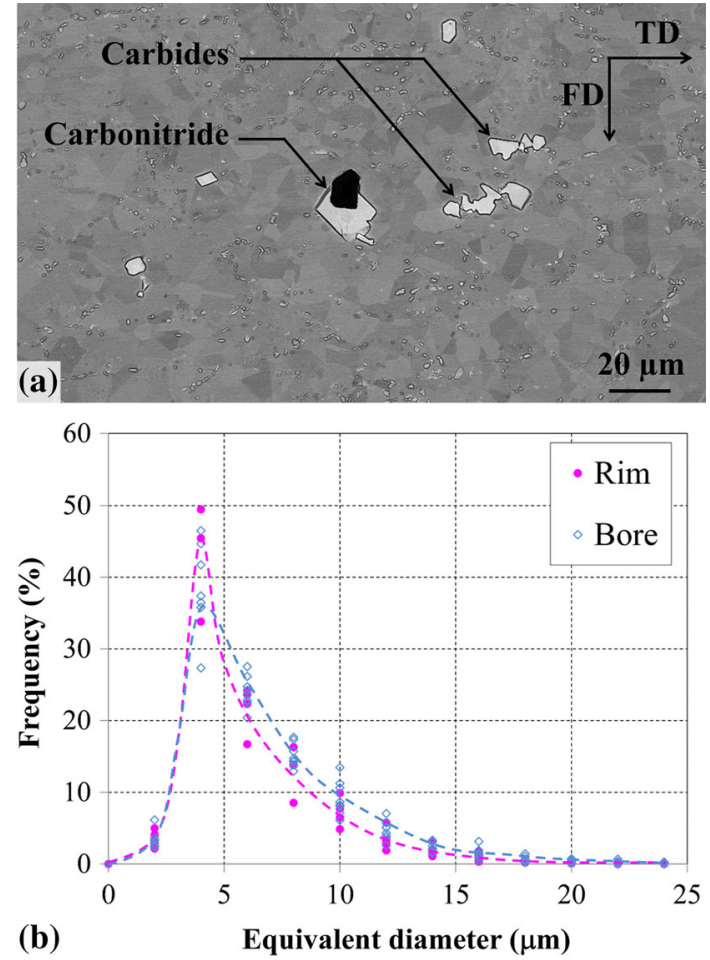

Fig. 5-(a) Microstructure of some non-metallic inclusions, (b) Distribution size of non-metallic inclusions for the rim region and the bore region of the disk.

$\left[f_{\text {rim }}(\delta\right.$-phase $\left.)=6.9 \pm 1.0 \mathrm{pct}\right]$ than the bore region $\left[f_{\text {bore }}(\delta\right.$-phase $)=2.9 \pm 0.5$ pct $]$. These latter values correspond to the mean value and the standard deviation measured in a number of different micrographs, respectively.

\section{Non-metallic inclusions}

Figure 5(a) illustrates a number of carbides, carbonitrides, and clusters of carbides. Image analyses were

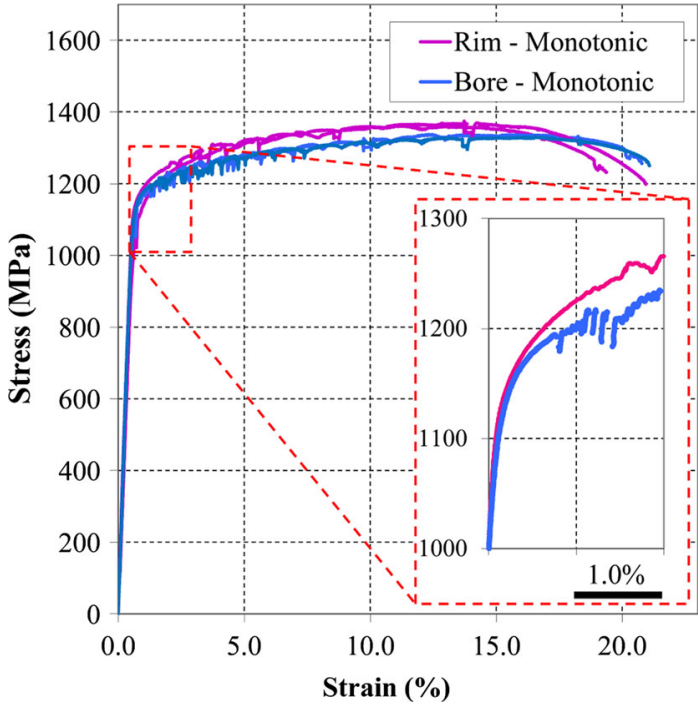

Fig. 6-Monotonic tensile behavior at intermediate temperature of the rim region (pink plots) and the bore region (blue plots) (Color figure online).

conducted on the different samples. The frequency of NMIs was plotted as a function of their size, whatever the nature of the NMI (Figure 5(b)). No significant changes in NMI distribution between the investigated regions of the disk were observed. Thus, the morphology and the mean size of the NMIs do not vary with location in the turbine disk.

\section{B. Conventional Mechanical Properties at Intermediate Temperature}

1. Monotonic tensile behavior

The monotonic tensile behavior of the rim and the bore regions was investigated at intermediate temperature (Figure 6). Both regions exhibit relatively small macroscopic differences in yield stress (Y.S.) and 
ductility (A pct). Slight variations in strain-hardening and ultimate tensile strength (U.T.S.) were observed between both the regions on the macroscopic tensile curves. An expanded view is inserted in Figure 6, which highlights the differences in monotonic behavior between the bore and the rim regions of the turbine disk. The 0.2 pct. offset yield strength is almost the same for the two regions of the disk (1132 and $1142 \mathrm{MPa}$ for the rim and the bore region, respectively). Several drops of stress were noticed in the plastic domain in both regions of the disk. This jerky flow is a manifestation of dynamic strain aging (DSA) associated to the Portevin Le-Chatelier effect. The plastic strain threshold over which this phenomenon occurs is lower for the bore region and at least 1.3 pct total strain, i.e., a higher strain level than the short lifetime LCF testing. Max et al. noticed a similar behavior in this range of strain rate at temperatures below $773 \mathrm{~K}\left(500{ }^{\circ} \mathrm{C}\right) .{ }^{[33]}$ The difference in critical strain for the onset of the first serration might result from minor local variations in the chemical composition.

\section{LCF lifespan}

Several LCF tests were performed at intermediate temperature up to failure on the different regions of the turbine disk in the same fatigue conditions to investigate the fatigue life at low-strain amplitude levels. The stabilized alternating stress amplitude, normalized by the yield stress, was reported as a function of the number of cycles to failure $N_{\mathrm{f}}$ (Figure 7). The rim region exhibits a higher lifespan in the present LCF conditions in comparison with the bore. Moreover, abnormally short lifetimes were only noticed for the bore region. The drop in lifetime is one order of magnitude compared to the mean lifetime of this region.

\section{3. $L C F$ behavior}

Additional LCF tests were performed in the $\varepsilon_{\text {plastic } \max }=0.12$ to $0.45 \mathrm{pct}$ range at intermediate temperature to assess the cyclic strain-hardening

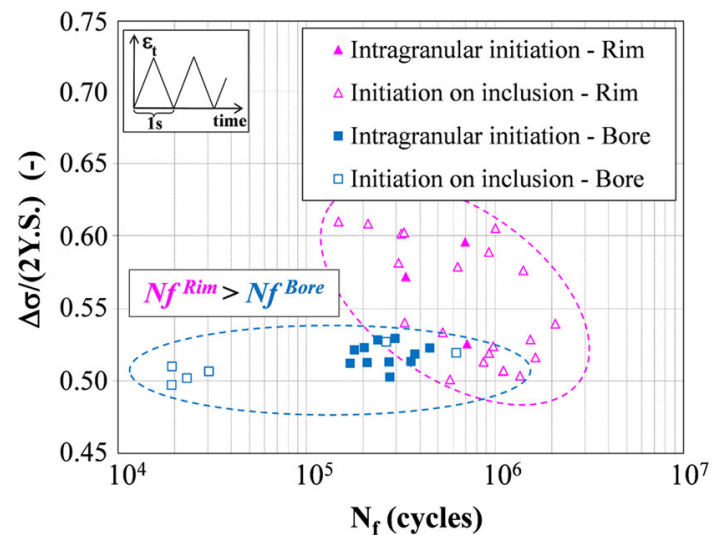

Fig. 7-Low-strain range level LCF behavior at intermediate temperature of the rim region (triangle markers) and the bore region (square markers) with a strain ratio $R_{\varepsilon}=0.05$ and a frequency $f=1 \mathrm{~Hz}$. The nature of the initiation site is reported for each test (filled markers and none-filled markers for crack initiation within grain and non-metallic inclusion, respectively). behavior of both the regions. The hysteresis loops stabilized at midlife, and a cyclic stress-strain curve was obtained as shown in Figure 8. Each point of the curve corresponds to one LCF experiment. A RambergOsgood approach was used to fit the cyclic strain-hardening curve for each region of the turbine disk. The modeled cyclic strain-hardening behaviors of each region under these LCF conditions are shown as dashed lines in Figure 8. Monotonic tensile behavior is also reported for comparison (solid lines). Both the regions exhibit cyclic softening with respect to the monotonic strain-hardening curves. This behavior has previously been reported and has been attributed to $\gamma^{\prime \prime}$ precipitate shearing processes. ${ }^{[2]}$ However, for high strain amplitudes, the cyclic strain-hardening in the rim region seems to be significant enough so as to result in comparable and even in higher stresses than the monotonic curve. Despite similar monotonic strain-hardening behavior (see Figure 8), cyclic strain hardening is measurably different for both the regions of the turbine disk. This observation highlights distinct deformation (dislocation) mechanisms in the rim compared to the bore regions under monotonic and cyclic stresses.

\section{Deformation and Damage Mechanisms}

\section{Analysis of fracture areas}

SEM observations of the specimen fracture surfaces were carried out in order to identify the nature of the initiation sites. Two different failure modes were identified, i.e., within coarse grains in the bulk or at (sub)-surface NMIs. Figure 9 shows a particular example of an initiation site at a cluster of nitrides, which resulted in an abnormally short LCF lifetime.

EDX mapping was also performed on the initiation site areas of different specimens with short LCF lifetimes. Elemental maps shown in Figure 10 clearly demonstrate differences in chemistry between the initiation site and the surrounding area due to the NMIs. In

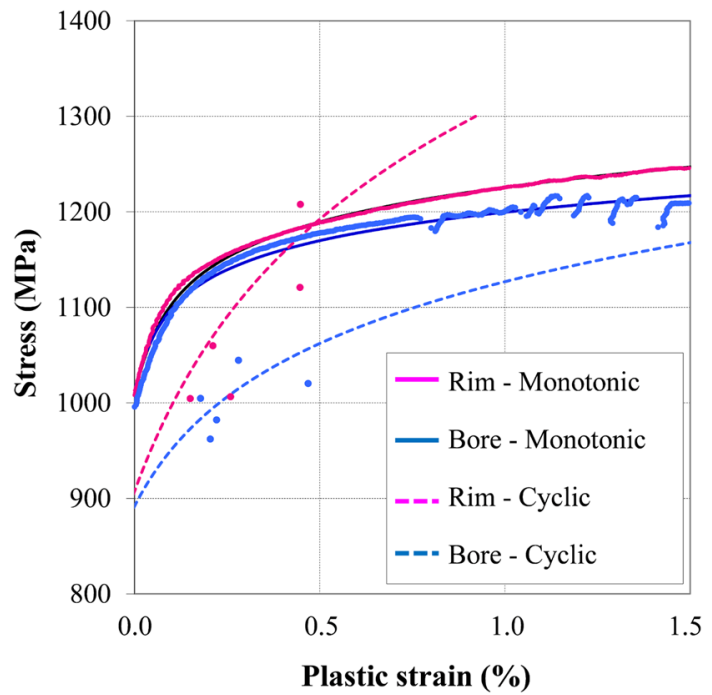

Fig. 8-Monotonic (solid line) vs cyclic (dashed lines) tensile behavior at intermediate temperature of the rim region (pink plots) and the bore region (blue plots) (Color figure online). 


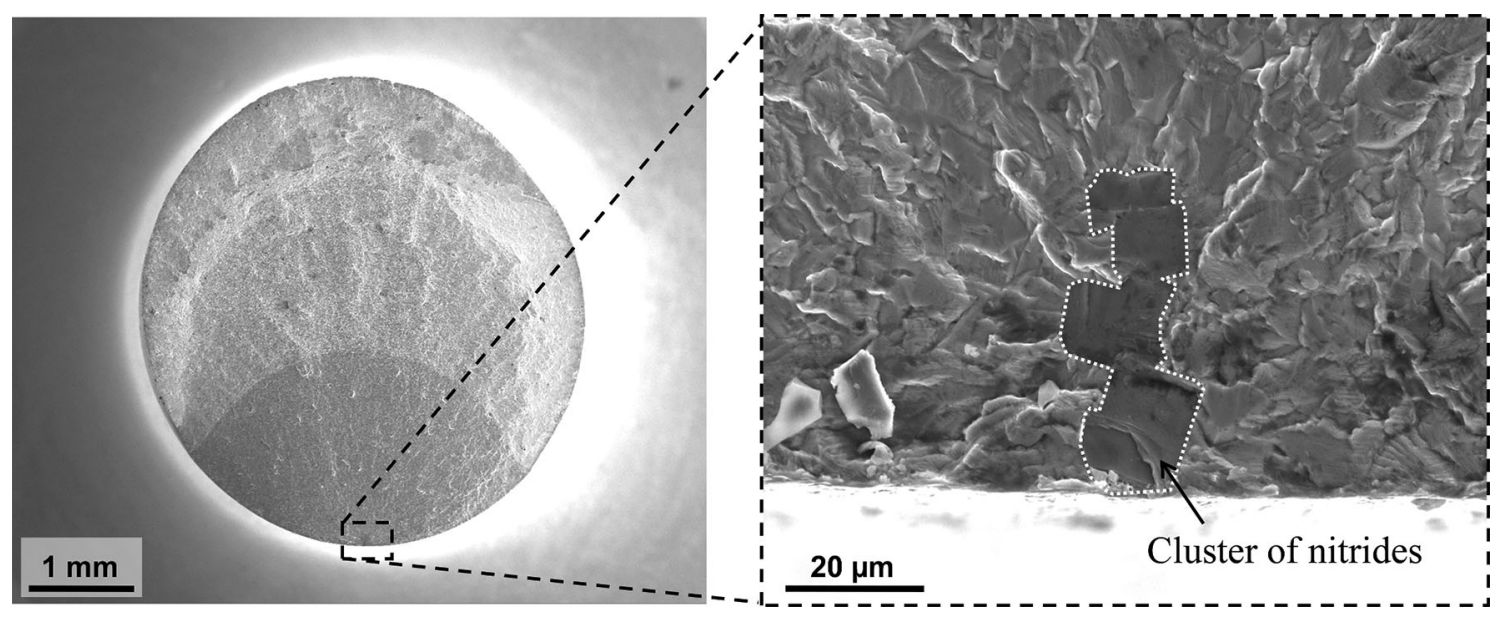

Fig. 9-Fracture area of a short LCF lifetime specimen: (a) Low magnification showing initiation site located at the surface of the specimen, (b) Cluster of nitrides identified as the initiation site.
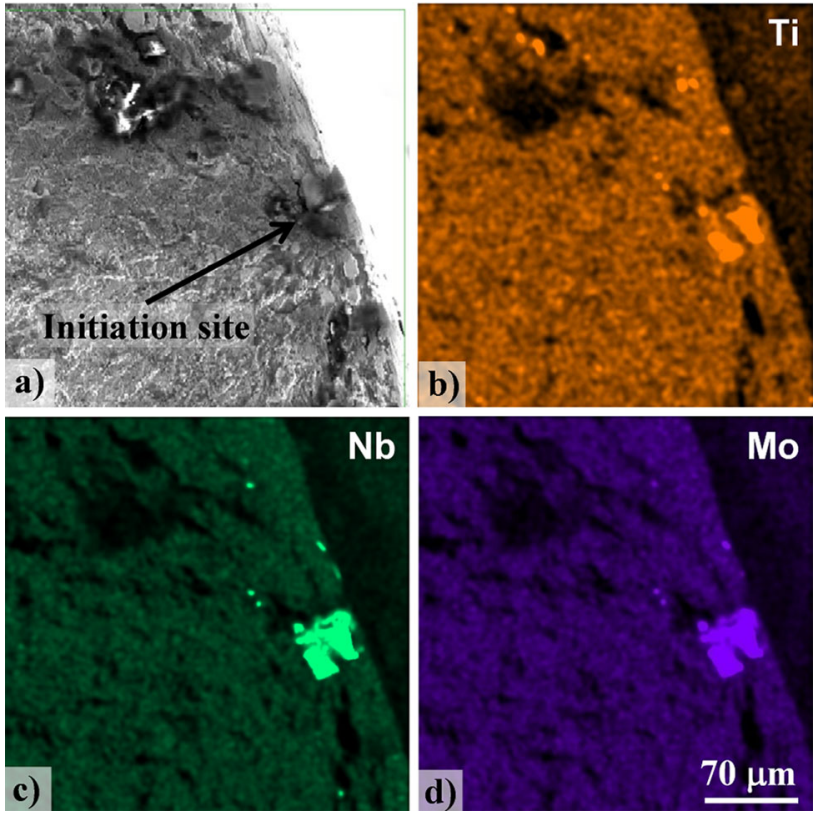

Fig. 10 - Chemical analyses of the nature of an initiation site of a short LCF lifetime: (a) SEI-SEM observation of the zone of interest, (b) EDX mapping of $\mathrm{Ti}$ content, (c) Mapping of $\mathrm{Nb}$ content, (d) Mapping of Mo content.

this particular example, the initiation site corresponds to an isolated carbide according to the molybdenum and niobium contents. The nature of the initiation sites is shown in Figure 7 as a function of lifetime. Interestingly, all the abnormally short lifetimes were due to NMI initiation. Conversely, crack initiation occurring at a (sub)-surface NMI does not necessary result in an abnormally short lifetime. Moreover, both single NMIs or clusters of NMIs can be at the origin of a premature failure. In these particular testing conditions, the rim region was shown to be more sensitive to crack initiation within NMIs than the bore region [P.o.f. ${ }^{\mathrm{Rim}}(\mathrm{NMI})=$ 0.83 and P.o.f. $\left.{ }^{\text {Bore }}(\mathrm{NMI})=0.35\right]$. Fractographic observations investigated the effect of the size of the initiation site on the fatigue life. Only (sub)-surface initiation site

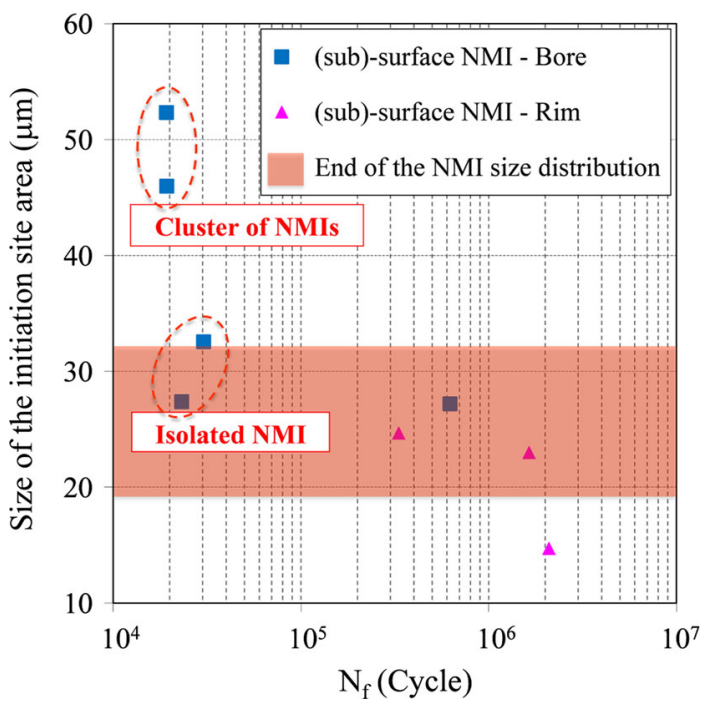

Fig. 11- Size of the initiation site area up to natural failure according to the lifetime.

within NMIs is presented in Figure 11 in order to compare similar stress concentration conditions in the vicinity of initiation site. It was shown that NMIs leading to the macroscopic failure are originated from initiation sites at the high end of the NMIs size distribution. In addition to this, fatigue lifetimes appeared to be sensitive to the NMIs size, especially when clusters of NMIs are in concern. Interestingly, failure did not necessary occurred due to initiation within the coarsest NMIs for longer lifespans.

\section{Interrupted fatigue tests}

The gage sections of samples were examined by SEM to determine the initiation/propagation life ratio in a series of interrupted LCF experiments under several different loading conditions. Only a few small cracks from non-metallic inclusions ( 5 to $10 \mu \mathrm{m}$ cracks) were observed, even at 97 pct of the life of one specimen. An example of such a small crack starting at a nitride is 


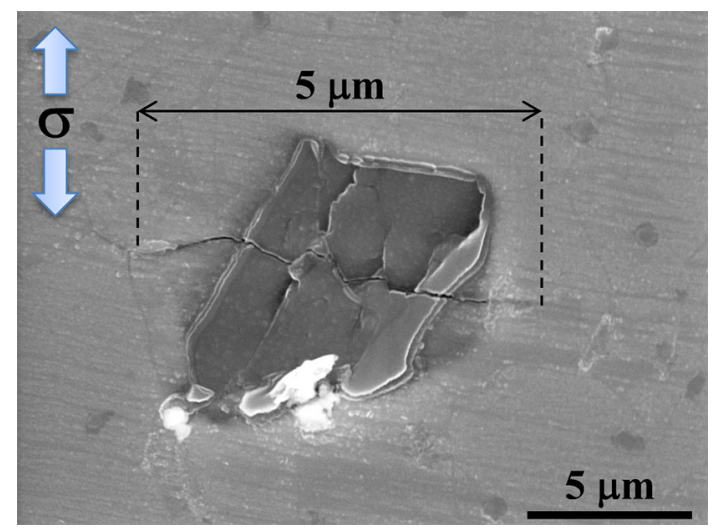

Fig. 12-Small crack propagating from a nitride of a rim region LCF specimen (97 pct of the lifetime).

shown in Figure 12. Other specimens dedicated to interrupted LCF experiments did not exhibit cracks at high fractions of life, even after several interruptions. From these observations, it can be concluded that the majority of the LCF life is spent in the crack initiation stage. The density of cracks on the gage zone after specimen failure is insignificant.

\section{Correlation of fatigue life with microstructural} features

The LCF lifespan results were analyzed on the light of quantitative analyses of different microstructural features, i.e., NMIs, $\delta$-phase, performed on the longitudinal cross-section of the gage zone of all the LCF specimens (see, e.g., Figure 13). As far as the NMIs are concerned, no significant trend was noticed for the effect of their mean size, whether in an isolated form or in clusters (non-filled markers in Figures 13(a) and (b)). The fraction of NMIs also does not directly influence the LCF lifetime (Figure 13(c)). The only noticeable correlation of life with NMIs was the deleterious effect of the coarsest non-metallic inclusions on the LCF lifetime (filled markers in Figure 13(a)). Interestingly, a lower $\delta$-phase content was also correlated with lower LCF lifetimes (Figure 13(d)). The relative contribution of each microstructural feature, i.e., the $\delta$-phase content or the end of the tail of the size distribution of NMIs, on abnormally short LCF lifetimes is however very difficult to establish quantitatively. A criterion which considers both features of microstructure is needed.

\section{SEM In Situ Testing: The Role of the Microstructure Surrounding Non-metallic Inclusions}

SEM in situ incremental tensile tests were conducted at room temperature in order to investigate $\mathrm{LCF}$ initiation conditions as well as local plasticity. In this approach, deformation mechanisms at temperatures below $773 \mathrm{~K}\left(500{ }^{\circ} \mathrm{C}\right)$ and at $293 \mathrm{~K}\left(20^{\circ} \mathrm{C}\right)$ are assumed to be similar, i.e., in the form of very planar intragranular slip, due to almost no viscoplasticity for this alloy in this range of temperature. ${ }^{[2,23]}$ Both the rim region and the bore region of the turbine disk were investigated.
1. Fracture of non-metallic inclusions on "as received" metallurgical states

The stress-strain curve and micrographs of the bore region are shown in Figure 14(a). The black dots on the curve correspond to the different steps at which observations have been carried out, while the micrographs in Figures 14(b) through (f) illustrate the evolution of fractured carbides under incremental loading. In this particular area, the first crack was observed at $1325 \mathrm{MPa}$. Numerous observations along sample gage lengths show evidence of the fracture of carbides at stress levels as low as $1000 \mathrm{MPa}$ for the bore region, while the first slip bands appear within coarse grains at $1150 \mathrm{MPa}$, i.e., $160 \mathrm{MPa}$ below the macroscopic yield strength. When the stresses are high enough for macroscopic yielding of the specimens, cracking of the NMIs rapidly increases.

Quantitative measurements of the fractured inclusions were performed on a statistically significant number of inclusions. The fraction of fractured NMIs as a function of the stress level is plotted as solid lines in Figure 15(a). As previously mentioned, the rim region exhibits a higher resistance to fracture of NMIs. Only a small fraction of the inclusions crack in the elastic and early plastic domain in both the microstructures. The damage progressively increases with the load up to saturation at around 85 pct. Not all the NMIs had failed even after 10 pet macroscopic plastic deformation.

\section{Fracture of non-metallic inclusions on pre-cycled} metallurgical states

The effect of cyclic stress relaxation on the NMI cracking was also investigated by SEM in situ tensile tests on specimens pre-cycled up to LCF midlife at intermediate temperature. Micro-tensile in situ specimens were extracted from the bulk of LCF specimens. The fraction of fractured NMI for pre-cycled materials as a function of the stress level is also plotted in Figure 15(a). Similar trends were noticed in comparison to the "as received" material. Limited NMI cracking was observed in the elastic domain, similar to the "as received" material. NMIs in the bulk region of the specimen were hence not already cracked due to the pre-cycling. Interestingly, the pre-cycled (dashed) curves shifted to higher stress levels for samples from both regions of the disk. This shift in stress level is higher $(170 \mathrm{MPa})$ for samples from the bore region. Differences between the as-received and the pre-cycled metallurgical states are mainly due to irreversible plasticity characteristic of LCF cycling at intermediate temperature. ${ }^{[2]}$ The stress-strain response was investigated in more detail to understand the stress level shift between the two metallurgical states. Due to the incursion into the plastic domain from the first cycle, compressive stress was measured during unstraining. Slight tensile plasticity was present from the second cycle and the amount of incremental plasticity decreased for the next few cycles, until reaching an elastic behavior after 5 to 10 cycles (Figure 15(b)). As a result, the maximum stress decreases over the LCF life down to a stabilized stress level. As mentioned before, the cyclic softening of IN718 is well known in the literature and attributed to the shearing of the $\gamma^{\prime \prime}$ hardening precipitates. ${ }^{[2]}$ The drop in 


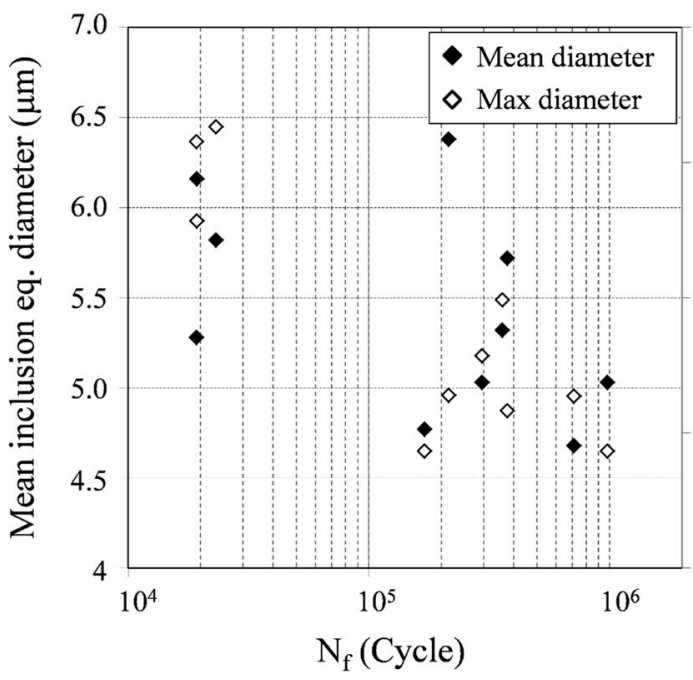

(a)

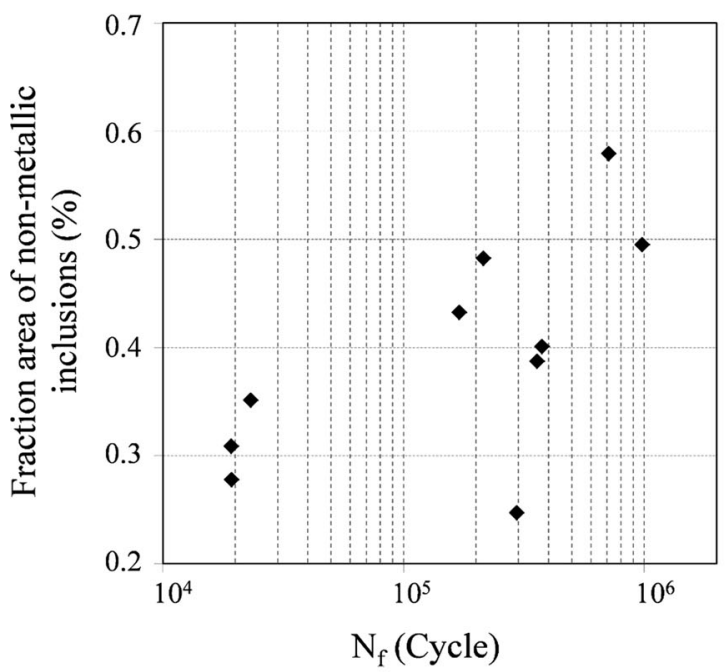

(c)

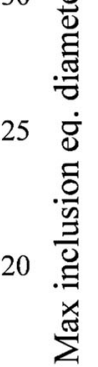
15

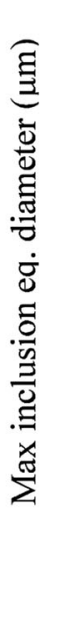
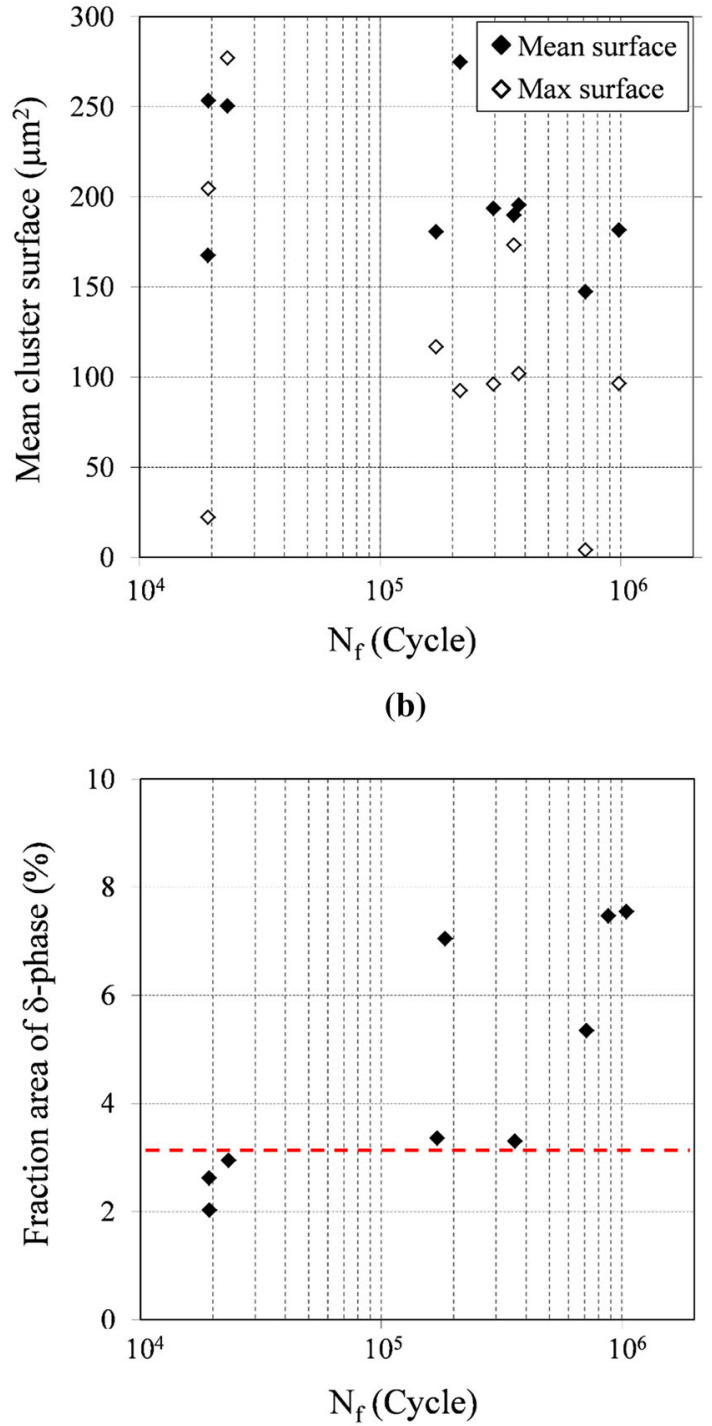

(d)

Fig. 13-Lifetime as a function of different microstructural parameters: $(a)$ Effect of the non-metallic inclusion size, $(b)$ Effect of clusters of non-metallic inclusions, $(c)$ Effect of non-metallic inclusion content, $(d)$ Effect of the $\delta$-phase content.

stress level between the first cycle and the stabilized stress during 0.67 pct strain amplitude LCF tests is about $80 \mathrm{MPa}$ for the rim region and $150 \mathrm{MPa}$ for the bore region, respectively (Figure 8 ). These latter values are in the same range than the shift in stress between the as-received specimen (solid lines) and the pre-cycled specimen (dashed lines) curves depicted in Figure 15.

\section{Damage transmission from non-metallic inclusions}

Room-temperature SEM in situ tensile tests allowed high-magnification observations of the transmission of damage from NMIs to the surrounding grain matrix. Step-by-step loading experiments were performed up to $1500 \mathrm{MPa}$, i.e., up to a 5 pct total strain. Micrographs of a fractured carbide are shown in Figure 16 at incremental stress levels. The failure of the carbide was first observed at a stress level of $1350 \mathrm{MPa}$. Slip offsets along a $\{111\}$ slip plane close to a twin boundary were noticed at this same stress level (Arrow in Figure 16(a)). At higher stress levels, a higher density of slip traces appears in the vicinity of the crack tip. However, the macroscopic strain for crack transmission from the carbide to the metallic matrix is relatively high $(0.6 \mathrm{pct}$ macroscopic plastic strain-Arrow in Figures 16(b) through (d)). The crack within the carbide experiences a higher degree of opening and local plasticity as the stress level is increased. Beyond $1425 \mathrm{MPa}$, the crack extends from the upper portion of the NMI into the matrix with the combination of two $\{111\}\langle-110\rangle$ slip systems. A similar behavior of cracks extending into the matrix at high stresses and a high level of local plasticity is observed in twenty other NMIs tracked during this interrupted straining process. These observations demonstrate that crack transmission from a NMI to the surrounding metallic matrix is relatively difficult and requires high local plastic strains. 

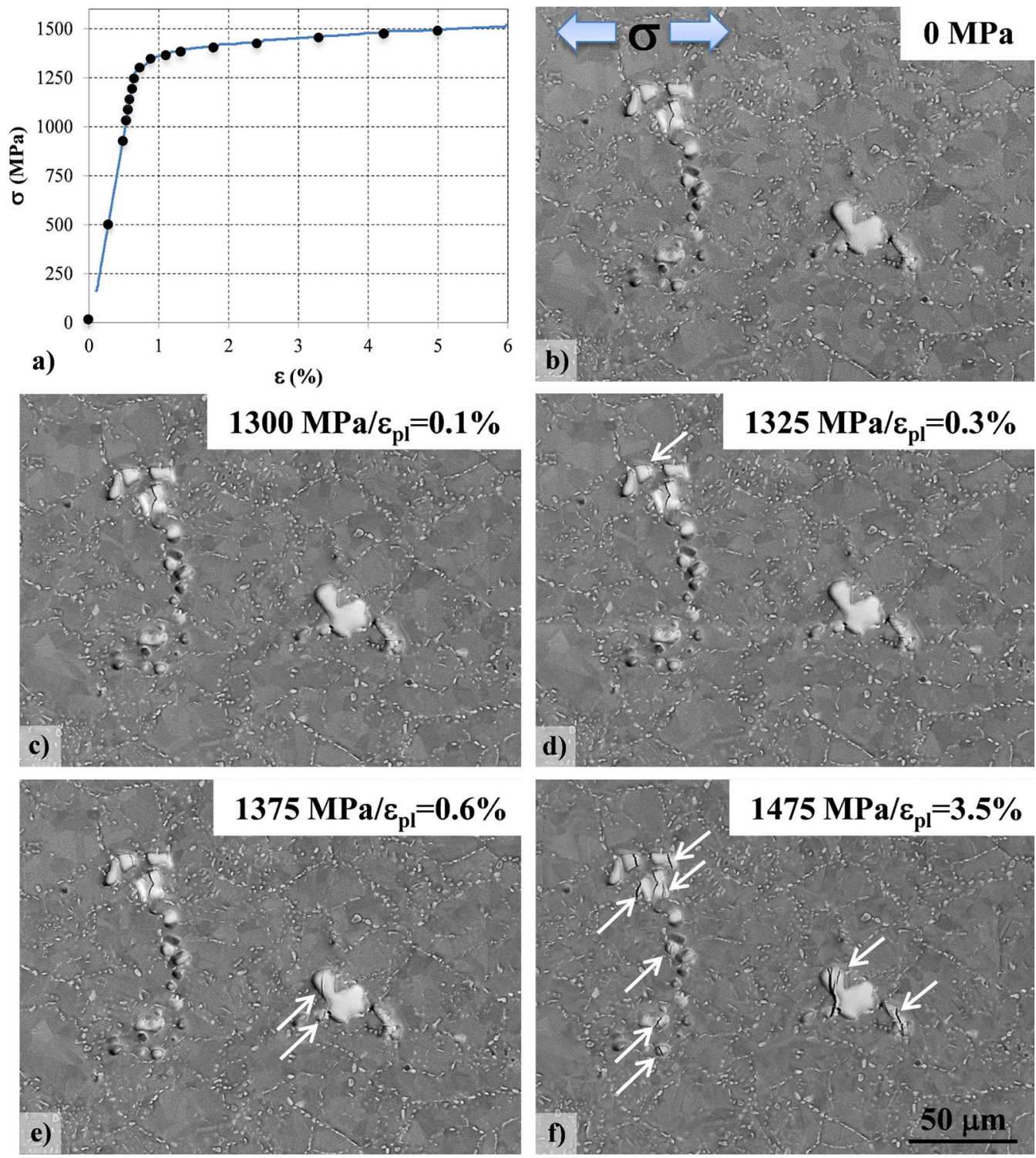

Fig. 14 -SEM in situ tensile test to assess the fracture behavior of non-metallic inclusions: $(a)$ Monotonic tensile behavior of the bore region at room temperature (each black dot corresponds to a dwell for crack density analysis). Evolution of an area with carbides for different loading conditions: (b) Initial state, (c) $1300 \mathrm{MPa},(d) 1325 \mathrm{MPa}$ (the white arrow highlights the occurrence of a crack), (e) $1375 \mathrm{MPa}$, (f) $1475 \mathrm{MPa}$.

\section{DISCUSSION}

In the current study, a strong variability in fatigue life of the direct-aged version of IN718 was measured at intermediate temperature in the low-strain amplitude regime (Figures 1 and 7). Under the loading conditions investigated, crack initiation and early crack growth consumed the majority of the cyclic life. Fractographic observations highlighted the deleterious character of (sub)-surface NMIs, in an isolated form or in clusters, on the fatigue life (Figures 9 through 11) leading to a ten- to hundred-fold reduction in fatigue life. However, cleavage of these (sub)-surface NMIs did not systematically lead to premature failure, since the process of propagating cracks from inclusions into the surrounding matrix was difficult, requiring high levels of local plasticity in the vicinity of the NMI. The major microstructural difference between the rim (longer life) and the bore regions (where abnormally short lives were observed) was the presence of a lower $\delta$-phase content and higher median and maximum grain size in the bore region. These results collectively suggest that a combination of "rare" features in the microstructure is important to the high level of variability observed in the fatigue life, including (a) the presence of NMIs from the high end of the size distribution, combined with (b) features that promote high local plasticity in the vicinity of a cracked inclusion, including locally low $\delta$-phase content and the presence of a grain from the high end of the size distribution that is favorably oriented for cyclic plastic straining. In the following sections, we consider the role of NMIs in the fatigue crack initiation process and the microstructure in the vicinity of the NMIs in the context of damage propagation. Aspects of the damage development process that require further quantification 


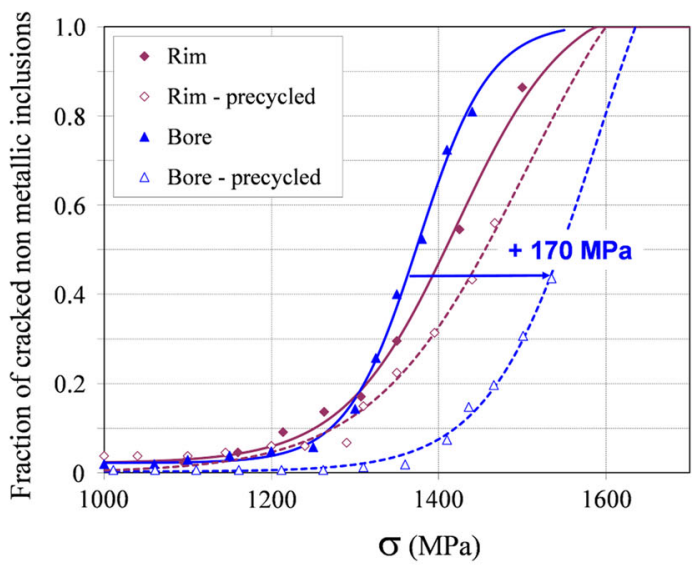

(a)

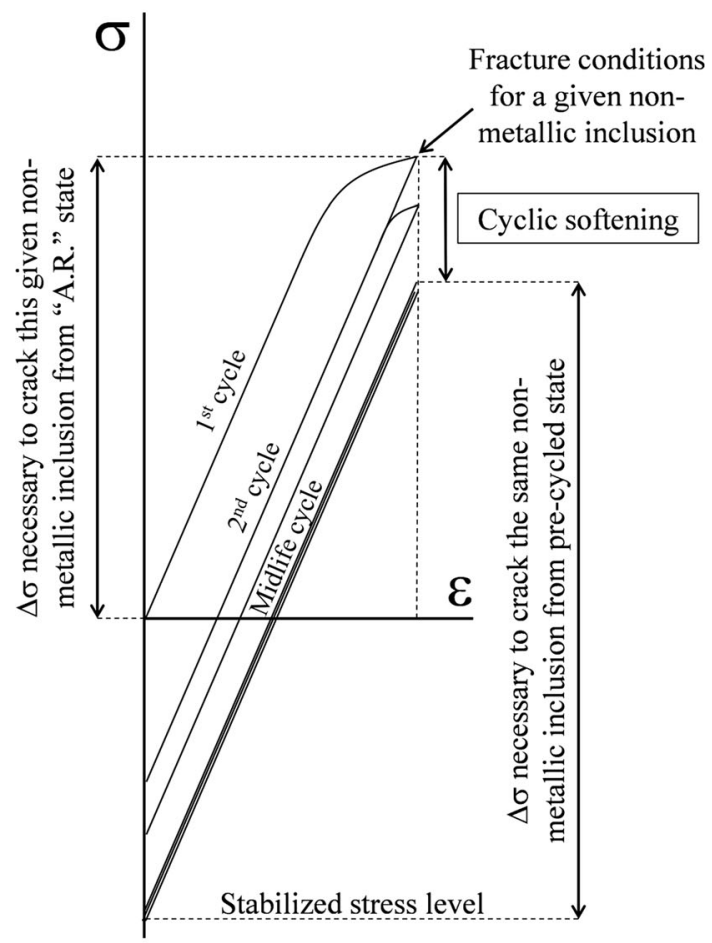

(b)

Fig. 15-(a) Fraction of fractured non-metallic inclusions as a function of the stress level. Blue and pink color codes correspond to the bore region and the rim region, respectively. The solid line and the dash line representations correspond to as-received specimens and LCF pre-cycled specimens, respectively. (b) Schematic explanation of the shift in stress to fracture a given NMI on a "as received" specimen and a pre-cycled specimen (Color figure online).

for the development of life prediction models are discussed.

\section{A. The Role of Non-metallic Inclusions in Crack Initiation}

NMIs exhibit a brittle behavior in the operating range of temperatures of IN718. ${ }^{[34]}$ Therefore, cleavage of these inclusions at the (sub)-surface was generally assumed to be the dominant failure mode, especially at low and intermediate temperature for fine-grain microstructure (ASTM 10 and finer microstructures). ${ }^{[10,12,14,17,18]}$ While a higher probability of failure within NMIs was noticed for the finer grain microstructure (Figure 7), i.e., the rim region microstructure [P.o.f. ${ }^{\text {Rim }}(\mathrm{NMI})=0.83$ and P.o.f. ${ }^{\text {Bore }}(\mathrm{NMI})=0.35$, abnormally short fatigue life occurred for the bore region microstructure. Therefore, the role of NMIs in crack initiation has to be discussed for both the microstructures. As depicted in Figure 11, a significant trend was found between the size of the initiation site and the fatigue life for (sub)-surface initiation sites within NMIs. Abnormally short fatigue lifespans were systematically due to crack initiation area whose size is from the high end of the NMI size distribution and even coarser due to clusters. Denda et al. evidenced a similar behavior by investigating the effect of electron beam cold hearth remelting (EBCHR) to lower NMI content in comparison with vacuum induction melted IN718 (VIM718), both with fine-grain microstructure (ASTM 10). ${ }^{[14]}$ In the present study, specimens were yet taken from the same wrought disk. Therefore, no variability in the NMI size distribution was observed between the rim and the bore regions of the disk, even for the end of the tail of the NMI size distribution (Figure 5). This microstructural parameter, although noteworthy, cannot explain itself the difference in the low-cycle fatigue variability between both the regions. The potential origins of crack initiation within (sub)-surface NMI will be discussed in terms of (i) surface integrity, (ii) NMIs oxidation, and (iii) thermal and mechanical mismatches between NMIs and the surrounding matrix.

i. Surface integrity was shown to strongly impact the fatigue life of wrought IN718 due to the introduction of residual stresses and due to numerous pre-cracked NMIs in the near surface region resulting from the machining process. ${ }^{[6,35-38]}$ In the present study, particular care was paid to machining and surface finishing of the specimens to achieve very low residual stresses in the near surface region and to remove any pre-cracked NMI from the lathe-turning operations. Abnormally short fatigue lifetimes are not expected to be due to surface preparation but rather to a material effect since all specimens were prepared consistently with the same procedure.

ii. Based on prior studies, surface degradation due to oxidation at intermediate temperature might be considered to be insignificant. Although oxidation of niobium rich carbides was demonstrated to promote crack initiation sites due to the high volume expansion associated to the $\mathrm{NbC}$ to $\mathrm{Nb}_{2} \mathrm{O}_{5}$ transformation under air condition above $823 \mathrm{~K}\left(550{ }^{\circ} \mathrm{C}\right),{ }^{[11,13,15]}$ Hong et al. shown that oxidation of carbides seemed to be insignificant in the very short fatigue life regime at temperatures below $773 \mathrm{~K}\left(500{ }^{\circ} \mathrm{C}\right)$ for tens of hours exposure time. ${ }^{[39]}$ Abikchi et al. noticed the occurrence of sporadic $\mathrm{Nb}_{2} \mathrm{O}_{5}$ eruptions at intermediate temperature for fatigue lives at least ten times longer than 

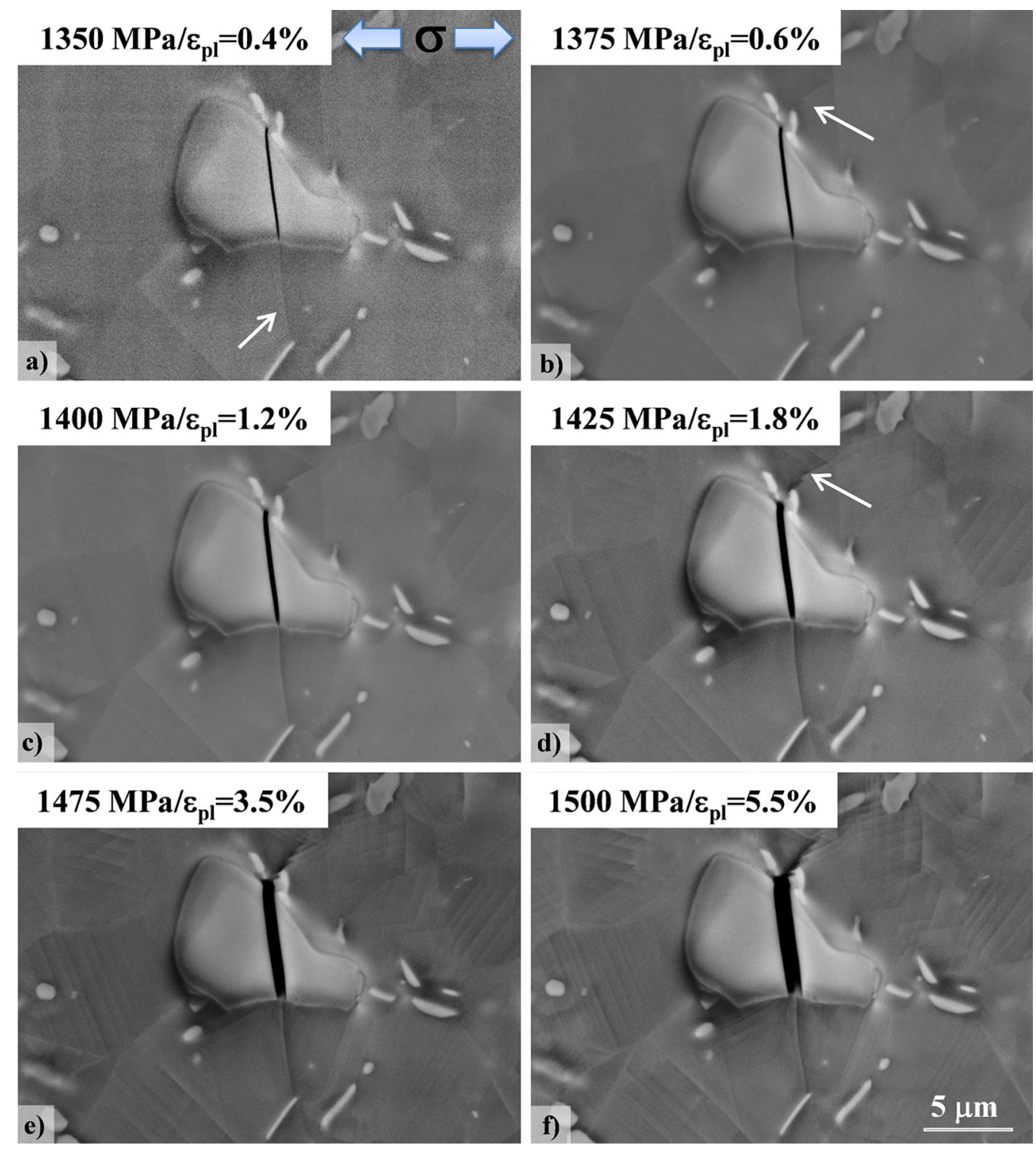

Fig. 16 - In situ tensile test to evaluate the ease of crack propagation from a NMI: High-magnification micrographs at different stress levels: (a) $1350 \mathrm{MPa}$, (b) $1375 \mathrm{MPa}$, (c) $1400 \mathrm{MPa}$, (d) $1425 \mathrm{MPa}$, (e) $1475 \mathrm{MPa},(f) 1500 \mathrm{MPa}$.

those of our abnormally short lifespans, without formation of short cracks from surface NMI. ${ }^{[19]}$ They surprisingly noticed internal crack initiation within coarse nitrides.

iii. Due to differences in elastic and thermal properties between carbides, nitrides, and the surrounding metallic matrix, stress concentration in the vicinity of NMIs might promote crack initiation. Karamched et al. measured by high-resolution EBSD analysis significant strain levels (about $1 \mathrm{pct}$ ) around carbides in a single-crystal nickel-based superalloy due to cooling after standard heat treatments. ${ }^{[40]}$ In addition to this, in situ tests conducted in the present study highlight two different mechanisms to induced NMI fracture at room temperature (Figures 14 through 16). An insignificant number of NMIs cracked without any emergence of slip bands within surrounding grains, which is coherent with the brittle behavior of NMIs. Above $1200 \mathrm{MPa}$, slip bands progressively emerged within grains according to their orientation with respect to the loading direction and the fraction of cracked NMIs rapidly increased. Confined plasticity brought by slip band activity within surrounding grains participates in NMIs fracture (see, e.g., Figure 16). This latter hypothesis is confirmed with our SEM in situ tensile characterization performed on pre-cycled specimens (dashed lines in Figure 15). Due to the softening behavior of IN718 under cyclic stresses at intermediate temperature (Figure 8), the required stress to crack a given NMI was shown to be higher for a pre-cycled specimen than for an "as received" specimen. 


\section{B. Microstructure in the Vicinity of NMI}

Slight variations in microstructural parameters were measured in the rim region of the disk compared to the bore. The bore regions exhibited a slightly coarser microstructure (Figures 3 and 4) with a lower content of $\delta$-phase (Figure 3 ). The rim region was shown to have better fatigue properties at intermediate temperature (Figures 7 and 8 ) despite a similar monotonic tensile response (Figures 6 and 8). According to Figure 8, differences in strength between the rim and the bore region were observed both under monotonic and cyclic conditions, which might witness different strengthening mechanisms. The $\gamma^{\prime \prime}$ microstructure was not directly assessed in the present study for each specimen but was characterized by inverse identification through the $\delta$-phase content. Since $\delta$ and $\gamma^{\prime \prime}$ have similar chemical compositions, the fraction and/or the size of $\gamma^{\prime \prime}$ precipitates were supposed to be function of the $\delta$-phase previously precipitated for a given chemical composition. Differences in the thermomechanical conditions between the rim and the bore regions of the disk promoted a higher $\delta$-phase content in the rim region. A specific analysis on each of the tested specimens enabled a correlation of the $\delta$-phase content with the fatigue life (Figure 13(d)). The strengthening properties of nickel-based superalloys generally play a role on the localization of strain incompatibilities at grain boundaries. Krueger et al. noticed, for instance, a higher stress relaxation for an underaged IN718 than for an overaged variant due to a lower degree of slip band strain localization. ${ }^{[18]}$ Materials having a higher fraction of strengthening precipitates are more prone to strain localization. In other words, a lower $\delta$-phase content might result in a lower stress relaxation in the vicinity of a NMI crack tip. Furthermore, notch sensitivity in IN718 was shown to be affected by the $\delta$-phase content and morphology, and minimized by an optimum $\delta$-phase microstructure. ${ }^{[21,41,42]}$ Therefore, both the $\delta$-phase content and the $\gamma^{\prime \prime}$ precipitation state might play a key role in premature failure and very short crack propagation from NMIs.

\section{Damage Transfer from Fractured Non-metallic Inclusions}

Extensive investigations of the fatigue properties and associated damage mechanisms in IN718 for a wide range of temperatures have led to the conclusion that a change in the fatigue behavior takes place above $773 \mathrm{~K}$ $\left(500^{\circ} \mathrm{C}\right) \cdot{ }^{[43,44]}$ Therefore, the characterization of the crack transmission from cracked NMIs to the surrounding metallic matrix at room temperature was justified as a means to understand damage transfer at intermediate temperatures. Numerous observations of fractured NMIs evidenced the difficulties of crack transmission from a fractured NMI under monotonic tensile stress (Figure 16). While the crack opening within the NMI continued to increase, slip bands in the matrix material adjacent to the NMI continued to develop for several percent of macroscopic plastic deformation without any propagation of the NMI crack into the matrix. These slip bands might have evolved into cracks under cyclic stresses. The difficulty in damage transfer from a fractured NMI was in agreement with the low crack density observed on the gage section after failure.

Finally, to develop fully predictive models for fatigue life, further information is needed on the process of crack transmission from NMIs to the surrounding $\gamma / \gamma^{\prime} \mid$ $\gamma^{\prime \prime} / \delta$ microstructure as a result of fatigue in IN718DA. This is likely to require a full 3-D analysis to capture the "rare" features of the microstructure around inclusions at the high end of the size distribution, including local grain orientation and the lengths of the slip planes along which strain localization is likely to occur as well as the precipitate sizes, fractions and morphology.

\section{CONCLUSION}

The variability in fatigue life of IN718DA in the low-strain range at a temperature below $773 \mathrm{~K}\left(500{ }^{\circ} \mathrm{C}\right)$ was analyzed based on a detailed microstructural characterization and mechanical tests to assess deformation and damage mechanisms at different scales. This investigation was conducted on two different microstructures (i.e., two regions) of a forged turbine disk. Low fatigue life was associated to surface and sub-surface initiation sites within non-metallic inclusions, i.e., carbides, nitrides, or carbonitrides. All surface inclusions however did not systematically lead to crack initiation and to short fatigue life. Fractographic observations highlighted the deleterious effect of the coarsest non-metallic inclusions on the fatigue life, while NMI size distribution was found to be similar for both the regions even for the tail end of the distribution. Slight differences in the grain size distribution between the rim region and the bore region of the disk are consistent with differences in yield stress and lifetime variability. Despite similar macroscopic monotonic tensile properties, significant differences in cyclic behavior were observed at very low plastic strain levels. The more pronounced cyclic softening of the bore region is related to differences in the $\delta-\gamma^{\prime \prime}$ precipitation state. Abnormally short fatigue life was systematically associated with a low $\delta / \gamma^{\prime \prime}$ ratio. Smaller stress relaxation close to fractured non-metallic inclusions with a low $\delta / \gamma^{\prime \prime}$ content ratio is believed to be the origin of such low LCF life at intermediate temperatures.

\section{ACKNOWLEDGMENTS}

The authors are particularly grateful to SnecmaSAFRAN group for providing the material and for financial support. The authors would like to thank Anne-Laure Gorge, engineer in the Department of Physics and Mechanics of Materials Department at the Institut Pprime, for fruitful discussions and technical help in conducting several experiments. 


\section{REFERENCES}

1. J.M. Oblak, D.F. Paulonis, and D.S. Duvall: Metall. Trans., 1974 vol. 5 , pp. 143-53.

2. D. Fournier and A. Pineau: Metall. Trans. A, 1977, vol. 8, pp. 1095-1105.

3. M. Sundararaman, P. Mukhopadhyay, and S. Banerjee: Acta Metall., 1988, vol. 36, pp. 847-64.

4. R.E. Schafrik and R. Sprague: Adv. Mater. Process., 2004, vol. 162 , pp. $27-30$.

5. D.F. Paulonis and J.J. Schirra: in Superalloys 718, 625, 706 and Various Derivatives, 2001, pp. 13-23.

6. N. Späth, V. Zerrouki, P. Poubanne, and J.Y. Guedou: in $S u-$ peralloys 718, 625, 706 and Various Derivatives, 2001, pp. 173-83.

7. Y.C. Fayman: Mater. Sci. Eng., 1987, vol. 92, pp. 159-71.

8. D.D. Krueger: in Superalloy 718 Metallurgy and Application, 1989 pp. 279-96.

9. Snecma-SAFRAN Database for LCF Tests Performed under Strain-Controlled Conditions.

10. P.R. Bhowal and A.M. Wusatowska-sarnek: in Superalloys 718 , 625, 706 and Derivatives, 2005, pp. 341-49.

11. T. Connolley, P.A.S. Reed, and M.J. Starinkm: Mater. Sci. Eng. A, 2003, vol. 340 , pp. $139-54$

12. B. Pieraggi and J.F. Uginet: in Superalloys 718, 625, 706 and Various Derivatives, 1994, pp. 535-44.

13. T. Connolley, M.J. Starink, and P.A.S. Reed: in Superalloys 2000 , 2000, pp. 435-44.

14. T. Denda, P.L. Bretz, and J.K. Tien: Int. J. Fatigue, 1992, vol. 14, p. 420.

15. F. Alexandre, R. Piques, S. Deyber, and A. Pineau: in ECF14, 2002.

16. F. Alexandre, S. Deyber, and A. Pineau: Scripta Mater., 2004, vol. 50, pp. $25-30$.

17. L.A. James: Eng. Fract. Mech., 1986, vol. 25, pp. 305-14.

18. D.D. Krueger, S.D. Antolovich, and R.H. Van Stone: Metall. Trans. A, 1987, vol. 18A, pp. 1431-49.

19. M. Abikchi, T. Billot, J. Crepin, A. Longuet, T.F. Morgeneyer, and A Pineau: in 13th International Conference on Fracture, 2013, pp. 1-11.

20. A. Devaux, L. Nazé, R. Molins, A. Pineau, A. Organista, J.Y. Guédou, J.F. Uginet, and P. Héritier: Mater. Sci. Eng. A, 2008 , vol. 486, pp. 117-22.

21. J.W. Brooks and P.J. Bridges: in Superalloys 1988, 1988, pp. $33-42$

22. J. He, S. Fukuyama, and K. Yokogawa: J. Mater. Sci. Technol., 1994, vol. 10, pp. 293-303.
23. A. Pineau and S.D. Antolovich: Eng. Fail. Anal., 2009, vol. 16, pp. $2668-97$

24. M.M. Shenoy, R.S. Kumar, and D.L. McDowell: Int. J. Fatigue, 2005, vol. 27, pp. 113-27.

25. J. Zhang, R. Prasannavenkatesan, M.M. Shenoy, and D.L. McDowell: Eng. Fract. Mech., 2009, vol. 76, pp. 315-34.

26. A. Mitchell: in Superalloys 718, 625, 706 and Derivatives, 2005, pp. 299-310.

27. A. Mitchell and T. Wang: in Superalloys 718, 625, 706 and Various Derivatives, 2001, pp. 81-91.

28. L.A. James and W.J. Mills: Eng. Fract. Mech., 1985, vol. 22, pp. 797-817.

29. S. Ponnelle, B. Brethes, and A. Pineau: in Superalloys 718, 625, 706 and Various Derivatives, 2001, pp. 307-19.

30. M. Sundararaman, P. Mukhopadhyay, and S. Banerjee: Metall. Trans. A, 1988, vol. 19, pp. 453-65.

31. S. Azadian, L.Y. Wei, and R. Warren: Mater. Charact., 2004, vol. 53 , pp. $7-16$.

32. J.-R. Vaunois, J. Cormier, P. Villechaise, A. Devaux, and B. Flageolet: in Superalloy 718 and Derivatives, 2010, pp. 199-213.

33. B. Max, B. Viguier, E. Andrieu, and J.M. Cloue: Metall. Mater. Trans. A, 2014, vol. 45A, pp. 5431-41.

34. D.L. Kohlstedt: J. Mater. Sci., 1973, vol. 8, pp. 777-86.

35. D. Dudzinski, A. Devillez, A. Moufki, D. Larrouquère, V. Zerrouki, and J. Vigneau: Int. J. Mach. Tools Manuf., 2004, vol. 44 , pp. $439-56$

36. D. Ulutan and T. Ozel: Int. J. Mach. Tools Manuf., 2011, vol. 51, pp. $250-80$.

37. S.M. Afazov, A.A. Becker, and T.H. Hyde: Int. J. Adv. Manuf. Technol., 2010, vol. 51, pp. 711-22.

38. P.R. Bhowal, D. Stolz, A.M. Wusatowska-Sarnek, and R. Montero: in Superalloys 2008, 2008, pp. 417-23.

39. J.K. Hong, N.K. Park, S.J. Kim, and C.Y. Kang: Mater. Sci. Forum, 2005, vol. 502, pp. 249-56.

40. P.S. Karamched and A.J. Wilkinson: Acta Mater., 2011, vol. 59, pp. 263-72.

41. M. Nageswara Rao: Trans. Indian Inst. Met., 2010, vol. 63, pp. 363-67.

42. M.J. Donachie and S.J. Donachie: SUPERALLOYS a Technical Guide, 2nd ed., ASM International, Materials Park, 2002.

43. J. Warren and D.Y. Wei: Mater. Sci. Eng. A, 2006, vol. 428, pp. 106-15.

44. T.H. Sanders, R.E. Frishmuth, and G.T. Embley: Metall. Trans. $A, 1981$, vol. 12, pp. 1003-10. 